Article

\title{
Achieving the Success of Sustainability Development Projects through Big Data Analytics and Artificial Intelligence Capability
}

\author{
Haili Zhang, Michael Song *(-) and Huanhuan He \\ School of Economics and Management, Xi'an Technological University, Xi'an 710021, China; \\ zhanghaili@xatu.edu.cn (H.Z.); 1705210386@st.xatu.edu.cn (H.H.) \\ * Correspondence: michaelsong@xatu.edu.cn
}

Received: 22 December 2019; Accepted: 26 January 2020; Published: 28 January 2020

check for updates

\begin{abstract}
There has been increased interest in studying how big data analytics capability (BDAC) and artificial intelligence capability (AIC) lead to sustainable innovation and performance. Yet, few studies have investigated how these two emerging capabilities affect the success of sustainability development projects through the mediating effects of the sustainability design and commercialization processes. Based on Day and Wensley's theoretical framework for diagnosing competitive superiority, we propose a research model to investigate how sustainability design and commercialization mediate the relationships between two emerging capabilities and sustainable growth and performance. To test the proposed research model, we collected empirical data from 905 sustainability development projects from China and the United States. This study makes theoretical and managerial contributions to sustainable development theory. The study findings reveal several interesting results. First, BDAC and AIC not only increase the proficiency of sustainability design and commercialization but also directly enhance sustainable growth and performance. Second, sustainability design and commercialization mediate the positive effects of BDAC and AIC on sustainable growth and performance. Finally, the empirical analyses uncovered several cross-national differences. For sustainability design, BDAC is more important than AIC in the United States, while AIC is more important than BDAC in China.
\end{abstract}

Keywords: big data analytics capability; artificial intelligence capability; sustainability design; commercialization; sustainable growth and performance

\section{Introduction}

Sustainable organizational growth and performance are hot topics in the literature. Past research has provided some insights into antecedents of sustainable growth and performance [1]. Recent research has suggested that big data analytics capability (BDAC) and artificial intelligence capability (AIC) are two emerging capabilities that contribute to the sustainability of organizational development [1,2]. Service innovation has also been suggested as an important driver of sustainable organizational growth and development [3,4]. The innovation literature has demonstrated that service innovation performance is positively associated with the quality of the service innovation process [4]. A high-quality service innovation process consists of a series of service development stages (e.g., service design and commercialization), and these stages have direct effects on innovation outcomes [4]. Higher proficiency in service design and commercialization helps companies to achieve sustainability of innovation and organizational growth. Marketing and technical capabilities have been shown to have positive effects on the proficiency of service design and commercialization [5,6]. Yet, having these capabilities does not guarantee innovation success [6,7]. Organizations must employ the capabilities to create sustainable competitive advantages $[1,6,7]$. 
Prior studies have suggested that big data are important sustainable resources for enterprises because they need new technologies to manage and analyze massive data and information [1]. The emergence of BDAC and AIC has changed the original production and operation mode of enterprises. BDAC and AIC can promote sustainable development in many fields, including the Internet of Things, social networks, sustainable development, and sustainable investment in the supply chain [1]. Many organizations invest in the development of BDAC and AIC to improve their market competitiveness in order to survive [8]. Because BDAC can help organizations extract valuable information from big data, it can help organizations improve operational efficiency and sustainable growth and performance [1]. However, researchers have suggested that if organizations do not pay attention to the sustainability of BDAC, the social impact will be temporary [1,2].

Empirical research on BDAC and AIC thus far has focused mainly on how these capabilities affect sustainable organizational performance and sustainable competitive advantage. Some studies have shown that BDAC has a direct positive impact on sustainable organizational performance [1,9-11] and sustainable competitive advantage [1,12]. Other research has suggested that the relationship between BDAC and sustainable organizational performance is mediated by several variables [10,11]. Several studies have suggested that artificial intelligence can help organizations make production plans and monitor production quality [13]. Yet, few studies have explored the impact of AIC on the service innovation process, such as service design and commercialization [for exceptions, see [1,14,15]. Most of the existing research of AIC has focused on the technical aspects of the artificial intelligence. Very few studies have directly studied AIC and no measurement for AIC exists. To achieve sustainable development goals, it is also important to study how BDAC and AIC jointly affect the proficiency of the innovation process (sustainability design and commercialization) and sustainable growth and performance.

Although sustainability design and commercialization are the two most important stages in the service innovation process [4], to our knowledge few extant studies have examined the importance of BDAC and AIC in the service innovation process and how sustainability design and commercialization affect sustainable growth and performance of sustainability development projects. Hao et al. [1] recently emphasized the importance of including AIC together with BDAC to study the joint effects on sustainable innovation performance. Therefore, three research questions are developed for this study:

RQ1: How do BDAC and AIC together affect the sustainability design and commercialization of sustainability development projects?

RQ2: How do sustainability design and commercialization influence the sustainable growth and performance of sustainability development projects?

RQ3: How do sustainability design and commercialization mediate the relationships between BDAC and AIC and sustainable growth and performance of sustainability development projects?

To answer these research questions, we develop a theoretical model based on the sourceposition-performance (SPP) theoretical framework developed by Day et al. [16]. The SPP model is a widely accepted framework for diagnosing competitive superiority in top academic journals [6,7]. According to the SPP model, sources of advantages include superior capabilities that "represent the ability of a business to do more or do better (or both) than its competitors" ([16], p. 2). Capabilities do not automatically convert into sustainable performance. They must be deployed to "design, product, market, deliver, and service a product" ([16], p. 3) in order to create sustainable positional advantages and enhance sustainable performance. The proposed theoretical model predicts that BDAC and AIC are two emerging capabilities that enhance sustainable performance through increasing the proficiency of sustainability design and commercialization.

Because AIC is not available in the literature, we develop a new scale for measuring AIC based on the artificial intelligence literature. To validate the new AIC measurement scale and test the proposed theoretical model, we collect empirical data for 516 sustainability development projects in China. 
To further evaluate the generalizability of our findings, we conduct a second research project, where we collect data from 389 sustainability development projects in the United States. The empirical data include five industries: (1) hotel, traveling, and tourism services; (2) banking, insurances, securities, financial investments, and related activities; (3) information and semiconductors; (4) Internet-related services; and (5) health care services.

This study makes several theoretical contributions to the literature on sustainable development. Our results extend the staged service innovation model (SIM) [4] and enrich the empirical research on BDAC and AIC [9-11]. This study also provides insights for managers of sustainability development projects. Finally, this study contributes to cross-national research by identifying similarities and differences between China and the United States.

\section{Literature Review}

\subsection{Big Data Analytics Capability (BDAC)}

BDAC refers to "a firm's ability to assemble, integrate, and deploy its big data-specific resources" [17]. BDAC can help companies effectively mobilize, deploy, and use big data analytics resources [8]. It can also combine big data analytics with corporate strategy to gain a sustainable competitive advantage and improve organizational performance [12]. There are three dimensions of BDAC: (1) management capabilities, technical capabilities, and talent capabilities [9,11]; (2) tangible resources, intangible resources, and human resources [17]; and (3) big data management and technology capabilities [10]. Prior research has suggested that BDAC can help companies obtain and use market information to meet customer demand and play a key role in the innovation process [18].

Empirical research on BDAC thus far has focused mainly on its impact on sustainable organizational performance and sustainable competitive advantage $[1,8,19]$. Some studies have shown that BDAC has a direct positive impact on organizational performance [1,9-11] and sustainable competitive advantage [20]. For example, Ferraris et al. [10] and Akter et al. [9] found that BDAC has a positive impact on firm performance. Wamba et al. [11] revealed that BDAC increases financial performance and market performance. Results from Dubey et al. [20] suggested that higher levels of BDAC lead to better competitive advantages. Other studies have found that knowledge management [10] and process-oriented dynamic capabilities [11] mediate the relationship between BDAC and sustainable organizational performance. Still other research has shown that the relationship between BDAC and sustainable organizational performance is moderated by some variables. For example, the consistency of BDAC and business strategy may strengthen the impact of BDAC on sustainable organizational performance [9], but organizational flexibility does not moderate this relationship [20]. In a recent cross-national study, Hao et al. [1] recently found that for U.S. innovation projects, BDAC strengthens the relationship between big data resources and sustainable sales growth and gross margin. However, for Chinese innovation projects, "when big data resource is low, increasing BDAC enhances sustainable sales growth and gross margin only up to a certain point; developing BDAC beyond that point decreases, not increases, sustainable innovation performance" [1]. To our knowledge, no studies have investigated how the service innovation process mediates the relationship between BDAC and sustainable growth and performance. Therefore, to achieve sustainable development goals, it is important to study how BDAC affects the proficiency of the innovation process (sustainability design and commercialization) and the sustainable growth and performance.

\subsection{Artificial Intelligence Capability (AIC)}

AIC refers to the ability of an innovation team to deploy artificial intelligence machines to imitate human cognitive functions and perform tasks in an intelligent manner [21], including problem solving and learning [22]. Artificial intelligence is an effective decision-making tool [23] and it has been applied to the field of innovation management to monitor quality, plan production [13], improve decision-making processes [23], increase productivity, and gain sustainable competitive advantages. 
The existing research on artificial intelligence focuses primarily on the calculation or tools of artificial intelligence, such as artificial neural networks [24,25], fuzzy logic [21], pattern recognition [21], machine learning [13,21,26], expert systems [13,21], and genetic algorithms [22], as well as the scope of application of artificial intelligence, such as medicine, manufacturing, system maintenance, and environmental pollution [13]. Most of the existing research has focused on the technical aspects of the artificial intelligence. Very few studies have directly studied AIC and no measurement for AIC exists.

Increasing AIC enhances the ability of an innovation team to analyze customer data, identify customer needs, find business opportunities, and design and market new service innovations that meet customer needs. However, few studies have explored the impact of AIC on the innovation process (for exceptions, see $[14,15])$ and, to date, no studies have investigated how BDAC and AIC jointly affect sustainable growth and performance. Hao et al. [1] recently called for future research to study how BDAC and AIC together affect sustainable innovation performance.

\subsection{The Innovation Process}

The staged service innovation model emphasizes the direct impact of the innovation process on service innovation performance [4]. This model divides the service innovation process into five stages (idea screening, business and market opportunity analysis, service design, service testing, and commercialization). Except for idea screening, the quality of other stages is found to have a positive effect on service innovation performance. Previous research suggests that service design and commercialization are the two most important stages of the service innovation process for improving sustainable innovation performance [4].

Scholars have identified many factors that affect the quality of the innovation process: (1) resource factors such as marketing resources [5-7] and technical resources [5-7]; (2) capability factors such as marketing capability [27], market-linking capability [27], technical capability [27], network capability, and organizational learning capability; (3) and contextual factors such as service characteristics, standardized service innovation processes, service innovation ability [28], and service innovation competitiveness [28]. Other studies have focused on internal and external environments of the organization, such as employee involvement [29], organizational structure [29], and customers and suppliers [30]. With few exceptions, most of the existing research has focused on traditional capabilities, such as marketing, technology, information technology, and management capabilities [27]. In the era of big data with emerging technologies, these traditional capabilities can no longer meet the needs of data extraction and processing for successful innovation [1]. Companies need to build BDAC and AIC to meet their needs for information processing and ultimately improve the proficiency of the innovation process.

In summary, the gaps in the literature are notable for several reasons. First, recent studies have shown that BDAC and AIC are the two most important emerging capabilities $[1,10,11,17]$. Second, the roles of these emerging capabilities in the innovation process are becoming increasingly prominent in both academic research and practice $[1,10,11]$. Third, both BDAC and AIC can help companies process the enormous amount of available data to identify market opportunities, predict customer needs, and analyze customer purchase decisions $[17,21]$.

\section{Theoretical Model and Research Hypotheses}

According to the SPP framework proposed by Day and Wensley [16], the sources of advantages (e.g., resources and capabilities) improve sustainable organizational performance through creating positional advantages. The SPP framework has been one of the most cited and influential theoretical frameworks in the marketing, management, and innovation literature $[6,7,31]$. The SPP framework has also been adopted in many innovation and entrepreneurship studies. For example, Zhao et al. [7] found that technical capabilities affect first product performance through mediating variables such as product differentiation. Zhao et al. [31] suggested that scalability and protectability together mediate the relationship between market-linking capability and performance and the relationship between 
service design capabilities and performance. Song et al. [6] adopted the SPP framework to study new product development in the United States and Japan. They linked the sources of advantages to the product innovation process and positional advantages and then to sustainable project performance.

Based on the SPP, we propose a theoretical model (Figure 1) to study the relationships between the two emerging capabilities (BDAC and AIC) and the sustainable growth and performance of sustainability development projects. We argue that BDAC and AIC represent the ability of a business to do more or do better (or both) than its competitors in design and commercialization [16]. The model suggests that BDAC and AIC must be deployed to "design, produce, market, deliver, and service a product" ([16], p.3) in order to increase sustainable growth and performance. Therefore, the proposed theoretical model predicts that BDAC and AIC are two emerging capabilities that enhance sustainable performance through the mediating effects of sustainability design and commercialization.

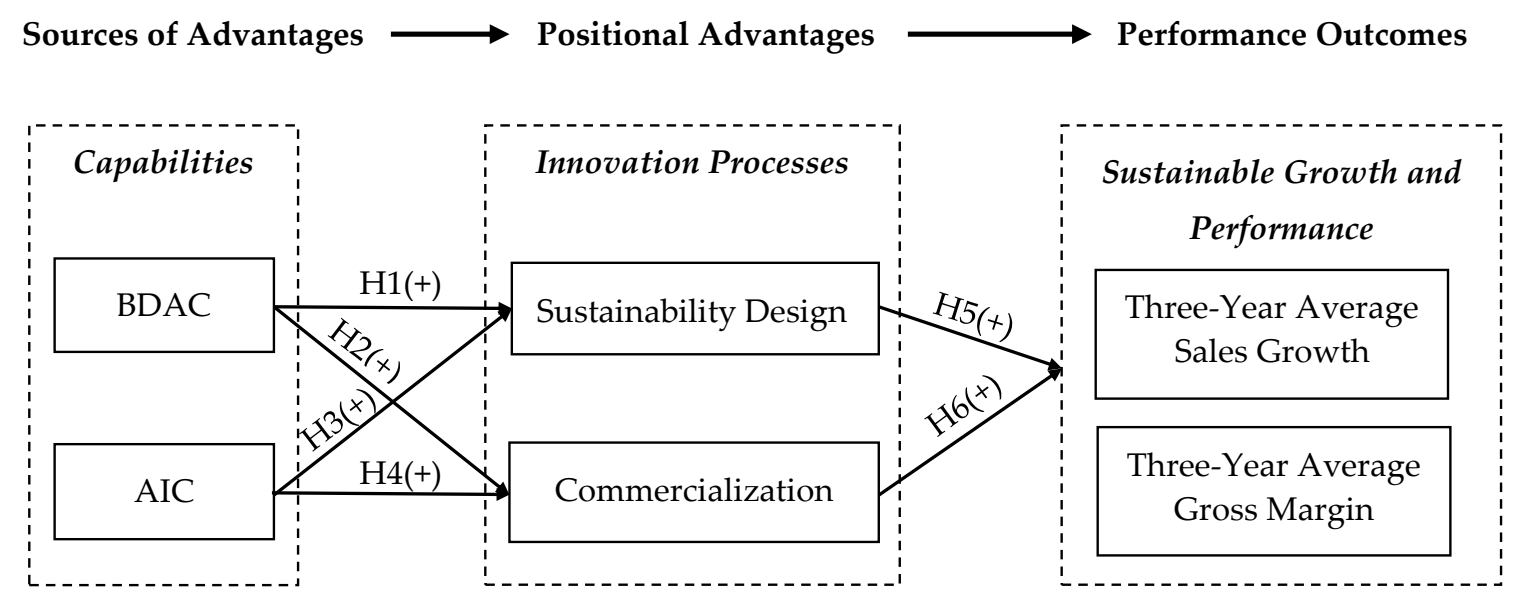

Figure 1. A theoretical framework for studying the effects of big data analytics capability (BDAC) and artificial intelligence capability (AIC) on sustainable growth and performance.

The model comprises six research hypotheses. Four hypotheses $(\mathrm{H} 1-\mathrm{H} 4)$ answer the first research question (RQ1): How do BDAC and AIC together affect the sustainability design and commercialization of sustainability development projects? Hypotheses $\mathrm{H} 5$ and $\mathrm{H} 6$ answer the second research question (RQ2): How do sustainability design and commercialization influence the sustainable growth and performance of sustainability development projects? Testing the mediation of sustainability design and commercialization answers the third research question (RQ3): How do sustainability design and commercialization mediate the relationships between BDAC and AIC and the sustainable growth and performance of sustainability development projects?

\subsection{Big Data Analytics Capability, Artificial Intelligence Capability, and the Innovation Process}

BDAC refers to the ability of companies to use advanced tools and capabilities to extract value from big data, discovering relationships and dependencies, performing predictions of outcomes and behaviors, and discovering new correlations to spot market demand trends and predict user behavior. Using big data resources enables managers to gain innovation strategies and make changes based on market demand [18]. Likewise, in the innovation process, managers can use big data to support innovation decisions to obtain strategic advantages over competitors [18].

Sustainability design aims to transform sustainability product concepts into marketable service offerings, including designing service innovation that it is easy to scale up and integrating state-of-the-art sustainable technologies or sustainable materials into the service design [4]. In the era of big data, one of the challenges faced by service design teams is that employees cannot fully understand and trust big data due to the lack of BDAC $[1,10]$. Because BDAC is an emerging capability, organizations must ensure that service design teams possess BDAC so that they can gain first-mover advantages by identifying customer needs and predicting customer behavior faster and more accurately than 
their competitors $[1,9,11]$. Previous studies have shown that companies with marketing advantages are more likely to achieve new product market success [5,6]. BDAC can improve the project team's ability to collect relevant market information and competitive information, enhance the team's ability to understand information, and provide effective guidance for service design [5,6]. In addition, service innovation faces a highly uncertain external environment, including rapid technological change, increased competition, changing customer demand, and legal and government regulatory changes [32]. BDAC can help companies extract real-time market data related to market needs and product usage [33] and identify changes in customer demand in a timely manner so that the innovation teams can make corresponding adjustments in the service design to better meet customer needs. Therefore, we hypothesize:

\section{H1: BDAC has a positive impact on the proficiency of sustainability design.}

During the project commercialization stage, the project development team makes plans of commercialization (e.g., final manufacturing and marketing plans), determines the overall direction of commercialization, and launches the project into the marketplace [4]. The commercialization stage requires project leaders to make important decisions, such as those regarding pricing, promotional programs, and targeted advertising [4]. Higher levels of BDAC enable project development teams to obtain better market information from big data $[17,20]$, identify information to differentiate their service products from those of their competitors, and provide guidance for the direction of commercialization [6]. BDAC also enables project teams to accurately understand and predict customers' needs [17]. Furthermore, BDAC helps project teams optimize their marketing programs, improve customer services, increase product competitiveness, and make better marketing decisions. At the same time, the deployment of BDAC creates a data-driven organizational culture that emphasizes the use of real-time information about changes in customer demand [11], accurately locating targeted customer groups, and adopting differentiated marketing methods to improve the proficiency of commercialization [4]. Therefore, we hypothesize:

H2: BDAC has a positive impact on the proficiency of commercialization.

AIC refers to the ability to use advanced techniques to simulate human intelligence behaviors to predict customer behavior; develop devices to replicate human intelligence and other cognitive functions; and develop artificial intelligence for learning, reasoning, and self-correction. Project teams with sufficient technical resources and skills can improve the quality of their product innovation process [6], but reliance only on resources does not directly affect the success of new products-instead, companies need the ability to make full use of resources to enable them to effectively compete in the marketplace [5].

AIC can help companies simulate human intelligence behaviors, understand customer needs, predict customer decisions [21,34], maintain good relationships with customers, and develop value propositions based on customer needs. High levels of AIC enable companies to gain relative competitive advantages and thereby improve the proficiency of service design in the innovation process [6]. Important functions of business intelligence include monitoring competitors' new designs and customer response to service design, and understanding key product characteristics and customer feedback, determining appropriate service design strategies [33], thus improving the proficiency of sustainability design. Therefore, we hypothesize:

\section{H3: AIC has a positive impact on the proficiency of sustainability design.}

AIC can improve the success of commercialization in several ways. First, AIC can help companies accurately predict customer decisions and customer behavior [21,34]. Understanding of customer needs, preferences, price sensitivity, and purchasing decisions can increase the success of marketing products and services [5]. Second, artificial intelligence technology can be deployed to automate many tasks and reduce the duplication and burden of sales staff, thereby making more sales staff available to engage in the work that cannot be replaced by artificial intelligence tools [22]. Third, artificial 
intelligence can help sales managers accurately locate target market segments, sell target products at appropriate prices, select appropriate distribution strategies to provide products to customers through advertising, promotion, and other promotional strategies, and make better marketing decisions [21,22]. Therefore, we hypothesize:

H4: AIC has a positive impact on the proficiency of commercialization.

\subsection{Innovation Process and Sustainable Growth and Performance}

Sustainability design aims to transform new service with sustainable technologies or/and sustainable materials into new service offerings [35]. The impact of design proficiency on the success of service innovation has been studied extensively, and a higher proficiency of design contributes to the sustainable performance of service innovation projects [4]. The proficiency of sustainability design is reflected mainly in how companies understand and meet customer demand, achieve scale-up, and integrate advanced sustainable technologies in the design process [4]. First, companies must fully understand customer needs in sustainable technologies during the design process and then incorporate the understanding into the service design to meet customer needs [35] to avoid product waste. Second, companies need to develop a clear value proposition to ensure that their service providers will be positioned for potential target groups, improve the acceptance of the target customer group to the new service, and then improve service performance [4]. Third, integrating the most advanced sustainable technologies in the service design will create first-mover advantages and barriers to competitors' entry into the market. Finally, a higher quality of design can reduce the cost of service production and offerings [35]. Therefore, we hypothesize:

H5: The proficiency of sustainability design has a positive impact on sustainable growth and performance.

Commercialization includes launching a product or service innovation into the marketplace, expanding production to achieve economies of scale, establishing customer orders and sales locations, and selling products to customers [35]. The objectives of the commercialization stage are to successfully launch the new service innovation into the market and increase the speed of innovation adoption. The proficiency of commercialization is affected by many factors, such as pricing, advertising, marketing, sales, and distribution decisions [4]. Empirical studies suggest that increasing the proficiency of commercialization will also improve product availability and market awareness, encourage more trials and repetitive purchases, and ultimately increase sales and market share [6,7]. Increased proficiency of commercialization will increase the quality of salesforce training, improve benchmark analyses of competitive offerings [7], and enhance target marketing. Finally, better commercialization increases the chances that customers have a better service experience and thus improves sustainable growth and performance. Therefore, we hypothesize:

H6: The proficiency of commercialization has a positive impact on sustainable growth and performance.

\section{Research Design}

To test our proposed theoretical model, we used a database that is part of a multiyear panel study of service innovation projects, which is reported in Hao et al. [1]. Because the focus of this study was on service innovations with sustainable technologies and products, from the data reported by Hao et al. [1], we selected only projects that were (1) 905 sustainability development projects (i.e., development projects incorporating sustainable technologies, sustainable products, or/and sustainable materials into the service design); (2) from either China or the United States (representing the two largest economics in the world); (3) from one of five target industries which offer a rich context for studying sustainability service innovation; and (4) for which we had sales growth and gross margin data for the three years after commercialization. Therefore, the data reported in this study are a subset of the data reported in Hao et al. [1]. 


\subsection{Overall Design}

The overall research design of Hao et al. [1] included three parts. First, to ensure the appropriateness of the research scales and methods for a cross-national study, we followed the standard procedures recommended by Douglas et al. [36] and extended by Song et al. [37], with six steps: (1) select appropriate research methods [37]; (2) develop sampling and survey management techniques and procedures [37]; (3) establish content validity of variables and hypothetical relationships between variables [37]; (4) develop and validate new scales [37]; (5) evaluate the equivalence of variables, concepts, scales, and samples [37]; (6) and assess potential cultural bias and response format bias [37]. Second, to test the causal relationships between variables, we first collected data on BDAC and AIC and industry characteristics; we then tracked the development projects over time and collected needed data on the innovation process. After commercialization, we continued to track the projects and collected sales and gross profits data for three years.

\subsection{Measurement Scale Development}

Because a scale for AIC is not available in the literature, we developed a new scale for measuring AIC based on the artificial intelligence literature using the measurement development procedures reported in Hao et al. [1]. The procedures are reproduced here for completeness.

We developed the measurement scale using the procedures reported in Song et al. [37]. We conducted face-to-face interviews with service innovation teams in China and the United States, follow-up interviews with team members, and consultations with academic experts. We used our findings to improve measurement scales from the literature and develop a new scale for AIC.

In the interviews, we examined the conceptual equivalence of the constructs with the first set of questions. Team members were requested to define the key constructs of BDAC, AIC, and the innovation process $[36,37]$. We assessed the functional equivalence of these constructs with the second set of questions. Team members also evaluated how well our theoretical model of the innovation process described their own innovation experience [36,37]. We examined the category equivalence of the constructs with the third set of questions, which addressed team members' perceptions of the relevance and completeness of the scale items from the literature and previous interviews [36,37]. The results of these interviews indicated that several scales should be modified.

Following Churchill's [38] recommendations, we asked four academic experts and 12 project managers in China and the United States to review our list of constructs and corresponding measurement items and provide critical assessments [37]. After some minor revisions, we constructed the final questionnaire. We had participants respond to each survey measure using a $0-10$ rating scale because feedback from interviewees suggested that this scale is easier to understand in international surveys compared to $1-7$ or 1-5 rating scales [39].

Our measurement scale for BDAC included five measures, which were adopted directly from Hao et al. [1]: (1) we have advanced tools (e.g., analytics and algorithms) to extract value from big data (adapted from $[17,20]) ;(2)$ we have the capability to discover relationships and dependencies from big data (new scale developed based on filed research); (3) we have the capability to perform predictions of outcomes and behaviors from big data (adapted from [17]); (4) we have the capability to discover new correlations from big data to spot market demand trends and predict user behavior (adapted from $[9,11]) ;(5)$ our big data analytics staff has the right skills to accomplish their jobs successfully (adopted from [17]). For responses on this scale, $0=$ no capability and $10=$ a very high level of capability. The BDAC data reported in this study were collected from the project leader and a senior manager who was in charge of the data management center in the organization. The BDAC variable was an average of the two ratings. Therefore, although these measures are the same as reported in [1], the data source differs from that of Hao et al. [1].

Our measurement scale for AIC had four measures: (1) we have the capability to simulate human intelligence behavior in making predictions of customer decisions (developed based on conceptualization in $[21,34])$; (2) we have the capability to develop human-inspired algorithms to 
predict customer behavior (adapted from [21]); (3) we have the capability to develop devices to replicate human intelligence and other cognitive functions (adapted from [40]); (4) we have the capability to develop artificial intelligence for learning (the acquisition of information and rules for using the information), reasoning (using rules to reach approximate or definite conclusions), and self-correction (new scale developed based on filed research). For responses on this scale, $0=$ no capability and $10=$ very high level of capability.

The sustainability design scale included five measures adopted from Song et al. [4]: (1) developing a clear value proposition of the service; (2) designing the service to ensure that it is easy to scale up; (3) designing the service to ensure that it delivers the promised value proposition; (4) integrating state-of-the-art technologies into the service design; (5) involving lead users in the service design process. For responses on this scale, $0=$ done very poorly or mistakenly omitted altogether and $10=$ done excellently.

The commercialization scale included five measures adopted from Song et al. [4]: (1) setting appropriate pricing level(s); (2) launching the service with strong promotional programs; (3) launching the service with effective advertising; (4) launching the service with excellent selling effort (e.g., the right people, properly trained, etc.); (5) launching the service with excellent distribution (e.g., on-time delivery, quick response, etc.). For responses on this scale, $0=$ done very poorly or mistakenly omitted altogether and $10=$ done excellently.

Sustainable growth and performance were measured with average sales growth and average gross margin, adopted from prior studies $[1,31]$. Sustainable development refers to "development that meets the needs of the present without compromising the ability of future generations to meet their own needs" [41]. Sustainable development has been divided into three dimensions: social, economic, and environmental $[1,41]$. To achieve the goals of sustainable development, companies need capital and the appropriate organizational environment. Because of this need for resources, often only economically profitable development projects can maintain their sustainability $[1,41]$. Under the condition of environmental protection and sustainable utilization of resources, organizations must improve the economic benefits to ensure the sustainability of their organizations. Sales growth and gross margin are important indicators to measure the benefits of innovation projects [31]. Therefore, as Hao et al. [1] suggested, using three years of sales growth and gross margin data to assess the sustainable growth and performance of sustainability development projects has some validity and support from the sustainability literature [1]. The Appendix A presents the entire measures with sources.

Past studies have suggested that innovation performance may be affected by industry characteristics $[1,4]$. Therefore, we included five industry dummies as control variables in this study.

\subsection{Data Collection}

The details of data collection were reported in Hao et al. [1]. To ensure that the participants in China and the United States would have the same understanding of the scale items, we used the double-translation method to translate the questionnaire [1]. The same as in [1], "two translators translated the English version into Chinese and then two other translators independently translated the Chinese version into English." The four translators resolved inconsistencies in the translations. We then conducted two pretests of the questionnaire, one in which participants completed the questionnaire in our presence and raised questions about unclear wording and another in which a professionally drafted questionnaire was sent to participants in the case study. Following the pretests, we made minor modifications to create the final questionnaire.

We administered the survey via express mail and e-mail, as reported in [1]. We first sent a package that included a personalized letter, the survey, and a prepaid return envelope or an e-mail with the letter and survey. A week later, we sent a follow-up letter/e-mail to each company to encourage their participation. After that, we sent up to two follow-up letters/e-mails and made phone calls to nonresponding companies in an attempt to improve the response rate. The characteristics of our two samples are presented in Table 1. Please note that the data reported selected for this study differ from 
those of Hao et al. in two aspects: (1) this study included only 905 sustainability development projects out of 1109 innovation projects reported in Hao et al. [1] and (2) the BDAC data reported in this study were from assessments of the project leader and a senior manager who was in charge of the data management center in the organization. The BDAC variable is an average of the two ratings.

Table 1. Characteristics of the respondents and the development teams.

\begin{tabular}{ccccc}
\hline & \multicolumn{2}{c}{ China $(\boldsymbol{N}=\mathbf{5 1 6})$} & \multicolumn{2}{c}{ U.S. $(\mathbf{N}=\mathbf{3 8 9})$} \\
\cline { 2 - 5 } & Mean & $\begin{array}{c}\text { Standard } \\
\text { Deviation }\end{array}$ & Mean & $\begin{array}{c}\text { Standard } \\
\text { Deviation }\end{array}$ \\
\hline Experience of the Project Leaders (year) & 12.845 & 3.705 & 12.650 & 3.378 \\
Design Experience (year) & 9.804 & 2.095 & 12.242 & 0.943 \\
Industry Experience (year) & 16.876 & 7.340 & 20.751 & 6.638 \\
Business Experience (year) & 19.025 & 7.038 & 13.650 & 5.976 \\
Number of Team Members & 14.008 & 3.310 & 15.519 & 4.046 \\
\hline
\end{tabular}

\subsubsection{Chinese Sample}

The initial Chinese sample frame comprised all 524 initial public offerings from 2004 to 2014 in the Small Medium Enterprise (SME) and Growth Enterprise Market boards in the Shenzhen Stock Exchange, China [42]. The sample was reduced to 482 companies due to missing data.

We contacted all the companies in the initial sample frame to request their participation in this cross-national research. The initial contact explained the purpose of this research and why the company was selected and offered research reports on how U.S. companies have achieved service innovation success. Each company was asked to provide information about four types of service innovation projects (a recently completed project, a successful project, a failed project, and a typical project). We continued with tracking and collecting data on the sales growth and gross margin for three years, ultimately collecting complete information for 632 service innovation projects from 278 companies.

Because the focus of this study was on innovation projects that incorporate sustainability concepts or technologies, projects needed to incorporate major sustainability technologies, sustainable products, or sustainable materials, or/and sustainable service concepts. From the 632 projects in the Chinese data set, 116 projects were not sustainable development projects and were excluded from this study. Therefore, the final Chinese data set for this study included only 516 sustainability development projects. The industry representation of the sustainability development projects included 33 from hotel, traveling, and tourism services; 180 from banking, insurances, securities, financial investments, and related activities; 95 from information and semiconductors; 70 from Internet-related services; and 138 from health care services.

All respondents were project leaders, except for BDAC, which also included rating from the senior manager in charge of the data division. The average sustainability development experience of the respondents was 12.845 years, the average design experience was 9.804 years, the average industry experience was 16.876 years, the average business experience was 19.025 years, and the number of team members ranged from 6 to 28 .

\subsubsection{U.S. Sample}

We selected our U.S. sample frame from the Dun and Bradstreet database. We used the same data collection process as described above for the Chinese sample and collected 477 service innovation projects. Of these 477 projects, 88 did not meet our criterion for inclusion of a major sustainability technology, product, or service concept and thus were excluded from this study. Therefore, the final U.S. data set included 389 sustainability development projects from 206 companies, with industry representation of 37 from hotel, traveling, and tourism services; 122 from banking, insurances, securities, financial investments, and related activities; 84 from information and semiconductors; 72 from Internet-related services; and 74 from health care services. 
All respondents were project leaders, except for BDAC, which also included rating from senior manager in charge of the data division: the average sustainability development experience of the respondents was 12.650 years, the average design experience was 12.242 years, the average industry experience was 20.751 years, the average business experience was 13.650 years, and the number of team members ranged from 6 to 25 .

\section{Empirical Analysis and Results}

\subsection{Construct Reliability and Descriptive Statistics}

We assessed the construct reliability using Cronbach's alpha and found that the values ranged from 0.795 to 0.997 , exceeding the recognized threshold value of 0.700 [35]. Thus, the variables had relatively high internal consistency and reliability. Tables 2 and 3 presents the mean, standard deviation, and correlation coefficient information for the variables of the Chinese and U.S. samples, respectively. Results from Table 2 indicate that all variables were significantly correlated with each other in the Chinese sample $(p<0.010)$. The correlation ranged from 0.119 to 0.886 . The correlation between BDAC and AIC was 0.451 and the correlation between sustainability design and commercialization was 0.119 . Similar to the Chinese sample, all variables in the U.S. sample were also significantly correlated with each other $(p<0.010)$. The correlation ranged from 0.249 to 0.929 . The correlation between BDAC and AIC was 0.277 and the correlation between sustainability design and commercialization was 0.249 . Consistent with prior research, we also found that average sales growth was highly correlated with average gross margin [1,31], both in the Chinese sample and the U.S. sample. Prior research suggests that these two measures are appropriate measures of sustainable growth and performance [1].

Table 2. Descriptive statistics and correlation coefficient matrix (Chinese sample, $N=516$ ).

\begin{tabular}{|c|c|c|c|c|c|c|}
\hline & 1 & 2 & 3 & 4 & 5 & 6 \\
\hline 1. Average Sales Growth (\%) & n.a. & & & & & \\
\hline 2. Average Gross Margin (\%) & $0.886^{* * *}$ & n.a. & & & & \\
\hline 3. Sustainability Design & $0.431^{* * *}$ & $0.433^{* * *}$ & 0.828 & & & \\
\hline 4. Commercialization & $0.307^{* * *}$ & $0.334^{* * *}$ & $0.119 * * *$ & 0.750 & & \\
\hline 5. BDAC & $0.412 * * *$ & $0.426 * * *$ & $0.467 * * *$ & $0.314 * * *$ & 0.796 & \\
\hline 6. AIC & $0.363^{* * *}$ & $0.321^{* * *}$ & $0.515^{* * *}$ & $0.322^{* * *}$ & $0.451^{* * *}$ & 0.810 \\
\hline Variables Means & 43.421 & 56.020 & 5.120 & 6.362 & 5.556 & 5.416 \\
\hline Standard Deviation & 43.705 & 28.954 & 2.456 & 1.874 & 2.233 & 2.337 \\
\hline Cronbach's $\alpha$ & & & 0.888 & 0.848 & 0.842 & 0.846 \\
\hline
\end{tabular}

Note: ${ }^{* *} p<0.01 ;{ }^{* *} p<0.05 ;{ }^{*} p<0.10$. Square root of AVE for multi-item scales is reported is on diagonal; n.a. represent not applicable because the scale is not multi-item scale.

Table 3. Descriptive statistics and correlation coefficient matrix (U.S. sample, $N=389$ ).

\begin{tabular}{|c|c|c|c|c|c|c|}
\hline & 1 & 2 & 3 & 4 & 5 & 6 \\
\hline 1. Average Sales Growth (\%) & n.a. & & & & & \\
\hline 2. Average Gross Margin (\%) & $0.929 * * *$ & n.a. & & & & \\
\hline 3. Sustainability Design & $0.341^{* * *}$ & $0.335^{* * *}$ & 0.828 & & & \\
\hline 4. Commercialization & $0.336^{* * *}$ & $0.362 * * *$ & $0.249 * * *$ & 0.993 & & \\
\hline 5. BDAC & $0.422 * * *$ & $0.421^{* * *}$ & $0.573 * * *$ & $0.328^{* * *}$ & 0.738 & \\
\hline 6. AIC & $0.335^{* * *}$ & $0.321^{* * *}$ & $0.404^{* * *}$ & $0.371^{* * *}$ & $0.277^{* * *}$ & 0.994 \\
\hline Variables Means & 51.914 & 77.877 & 5.045 & 5.825 & 5.587 & 5.507 \\
\hline Standard Deviation & 53.919 & 55.981 & 2.196 & 2.167 & 1.998 & 2.396 \\
\hline Cronbach's $\alpha$ & & & 0.897 & 0.997 & 0.795 & 0.996 \\
\hline
\end{tabular}

Notes: ${ }^{* * *} p<0.01 ;{ }^{* *} p<0.05 ;{ }^{*} p<0.10$. Square root of AVE for multi-item scales is reported is on diagonal; n.a. represent not applicable because the scale is not multi-item scale.

\subsection{Measurement Model Validation using CFA}

To evaluate the psychometric properties of the measurement models, we used AMOS 17.02 to perform confirmative factor analysis (CFA) using the procedure recommended by Anderson and 
Gerbing [43]. Evaluation of the fit indices and modification indices suggested that the U.S. model fit the data well. Thus, there was no need for further modifications. In contrast, we found that it was necessary to make two modifications to the measurement model for the Chinese sample. First, we allowed sustainability design (shorten for DESI) 2 to be correlated with DESI3 and DESI4. The estimated correlation was 0.271 between DESI2 and DESI3 and -0.661 between DESI2 and DESI4. Second, we allowed the error term of commercialization (shorten for COMM) 2 and COMM3 to be correlated. The estimated correlation was 0.511 . As indicated earlier, the original measurement model fit the U.S. data very well and thus no adjustments were made to the model. Tables 4 and 5 presents the results of the final measurement model validation using CFA.

Table 4. Results of measurement model validation using CFA for the Chinese sample $(N=516)$.

\begin{tabular}{|c|c|c|c|c|c|c|}
\hline $\begin{array}{l}\text { Construct } \\
\text { Items }\end{array}$ & $\begin{array}{l}\text { Unstandardized } \\
\text { Estimate }\end{array}$ & S.E. & Z-Value & $p$-Value & $\begin{array}{l}\text { Standardized } \\
\text { Estimate }\end{array}$ & AVE \\
\hline BDAC1 & 1.000 & & & & 0.875 & 0.633 \\
\hline BDAC2 & 0.901 & 0.035 & 25.446 & $* * *$ & 0.842 & \\
\hline BDAC3 & 1.066 & 0.034 & 31.615 & $* * *$ & 0.953 & \\
\hline BDAC4 & 0.477 & 0.053 & 9.044 & $* * *$ & 0.389 & \\
\hline AIC2 & 1.000 & & & & 0.841 & 0.656 \\
\hline AIC3 & 0.813 & 0.047 & 17.287 & $* * *$ & 0.730 & \\
\hline AIC4 & 1.014 & 0.048 & 21.110 & $* * *$ & 0.853 & \\
\hline DESI1 & 1.000 & & & & 0.828 & 0.685 \\
\hline DESI2 & 0.979 & 0.053 & 18.385 & $* * *$ & 0.800 & \\
\hline DESI3 & 0.928 & 0.047 & 19.623 & $* * *$ & 0.783 & \\
\hline DESI4 & 1.066 & 0.047 & 22.656 & $* * *$ & 0.895 & \\
\hline COMM1 & 1.000 & & & & 0.703 & 0.562 \\
\hline COMM2 & 0.912 & 0.058 & 15.776 & $* * *$ & 0.716 & \\
\hline COMM3 & 0.685 & 0.058 & 11.913 & $* * *$ & 0.540 & \\
\hline COMM5 & 1.196 & 0.071 & 16.777 & $* * *$ & 0.975 & \\
\hline $\begin{array}{l}\text { Overall Model } \\
\text { Fit Statistics }\end{array}$ & \multicolumn{6}{|c|}{$\begin{array}{c}\chi^{2} / \text { degrees of freedom }(\mathrm{df})=325.150 / 81=4.014 ; \mathrm{GFI}=0.928 ; \mathrm{CFI}=0.950 ; \mathrm{NFI}=0.934 ; \\
\text { IFI }=0.950 ; \mathrm{RMSEA}=0.077 .\end{array}$} \\
\hline
\end{tabular}

Table 5. Results of measurement model validation using CFA for the U.S. sample $(N=389)$.

\begin{tabular}{|c|c|c|c|c|c|c|}
\hline $\begin{array}{l}\text { Construct } \\
\text { Items }\end{array}$ & $\begin{array}{l}\text { Unstandardized } \\
\text { Estimate }\end{array}$ & S.E. & Z-Value & $p$-Value & $\begin{array}{l}\text { Standardized } \\
\text { Estimate }\end{array}$ & AVE \\
\hline BDAC1 & 1.000 & & & & 0.369 & 0.545 \\
\hline BDAC2 & 2.468 & 0.341 & 7.236 & $* * *$ & 0.876 & \\
\hline BDAC3 & 2.556 & 0.361 & 7.085 & $* * *$ & 0.916 & \\
\hline BDAC4 & 2.134 & 0.317 & 6.734 & $* * *$ & 0.662 & \\
\hline AIC2 & 1.000 & & & & 0.995 & 0.988 \\
\hline AIC3 & 0.984 & 0.007 & 136.585 & $* * *$ & 0.995 & \\
\hline AIC4 & 0.995 & 0.008 & 123.895 & $* * *$ & 0.993 & \\
\hline DESI1 & 1.000 & & & & 0.834 & 0.686 \\
\hline DESI2 & 0.949 & 0.054 & 17.690 & $* * *$ & 0.769 & \\
\hline DESI3 & 1.076 & 0.058 & 18.512 & $* * *$ & 0.835 & \\
\hline DESI4 & 1.047 & 0.052 & 20.048 & $* * *$ & 0.871 & \\
\hline COMM1 & 1.000 & & & & 1.000 & 0.987 \\
\hline COMM2 & 0.997 & 0.007 & 152.740 & $* * *$ & 0.992 & \\
\hline СOMM3 & 0.994 & 0.007 & 150.244 & $* * *$ & 0.992 & \\
\hline COMM5 & 1.007 & 0.007 & 141.548 & & 0.991 & \\
\hline $\begin{array}{l}\text { Overall Model } \\
\text { Fit Statistics }\end{array}$ & \multicolumn{6}{|c|}{$\begin{array}{c}\chi^{2} / \text { degrees of freedom }(\mathrm{df})=243.085 / 84=2.894 ; \mathrm{GFI}=0.926 ; \mathrm{CFI}=0.984 ; \mathrm{NFI}= \\
0.975 ; \mathrm{IFI}=0.984 ; \mathrm{RMSEA}=0.070 .\end{array}$} \\
\hline
\end{tabular}

The overall fit indices for the Chinese measurement model were: $\mathrm{GFI}=0.928 ; \mathrm{CFI}=0.950$; $\mathrm{NFI}=0.934 ; \mathrm{IFI}=0.950 ; \mathrm{RMSEA}=0.077 ;$ and $\chi^{2} /$ degrees of freedom $(\mathrm{df})=4.014$. For the U.S. 
sample, the overall fit indices for the U.S. measurement model were: GFI $=0.926$; CFI $=0.984$; $\mathrm{NFI}=0.975 ; \mathrm{IFI}=0.984 ;$ RMSEA $=0.070 ;$ and $\chi^{2} /$ degrees of freedom $(\mathrm{df})=2.894$. Consistent with prior studies [44-46], these fit indices indicate that the measurement models have reasonable fits with the data.

Construct convergent validity was established by the high Cronbach's alphas and the highly significant item-to-total estimates $(p<0.01)$. Results in Tables 2 and 3 suggest the lowest alpha (the lowest alpha was 0.842 for the Chinese sample and 0.795 for the U.S. sample).

To evaluate discriminant validity, we compared the average variance explained (AVE) with shared variance between different variables. Tables 2 and 3 present the correlations between different constructs in the lower left off-diagonal and square roots of AVE along the diagonal. The smallest square root of AVE (China: 0.750; United States: 0.738) was larger than the largest correlation coefficient (China: 0.515; United States: 0.573) for all multi-item scale variables. Therefore, discriminant validity was confirmed [46].

\subsection{Hypothesis Testing}

Because we wanted to explicitly test the mediating effects of sustainability design and commercialization using Sobel mediation tests, we chose to use ordinary least squares regression models to test the hypotheses instead of path models. Each scale used the average of all measures for the scale. Table 6 shows the regression results of the effects of BDAC and AIC on sustainability design and commercialization. The results in Table 6 provide answers to our first research question. Table 7 shows the regression results of the effects of sustainability design and commercialization on sustainable growth and performance. The results in Table 7 provide answers to our second research question.

As $\mathrm{H} 1$ predicted, the results in Table 6 suggest that the effects of BDAC on sustainability design are significant and positive $\left(\beta_{\text {China }}=0.323 ; \beta_{\text {U.S. }}=0.549 ; p<0.01\right)$, indicating that BDAC has a significant positive impact on the proficiency of sustainability design in both China and the United States. Thus, H1 was supported.

As H2 hypothesized, the results in Table 6 also show that BDAC has a significant and positive effect on the proficiency of commercialization $\left(\beta_{\text {China }}=0.178 ; \beta_{U} . S=0.265 ; p<0.01\right)$. That is, increasing BDAC enhances the proficiency of commercialization in both China and the United States. Thus, H2 was also supported.

As predicted in $\mathrm{H} 3$ and H4, the results in Table 6 suggest that the effects of AIC on sustainability design are 0.402 for China and 0.244 for the U.S. $(p<0.01)$ and that the effects of AIC on commercialization are 0.181 for China and 0.274 for the U.S. $(p<0.01)$, respectively. These results indicate that for both countries, AIC has a positive impact on the proficiency of sustainability design and commercialization. Therefore, H3 and H4 were supported.

Table 6. Regression results of BDAC and AIC on the innovation process.

\begin{tabular}{|c|c|c|c|c|c|c|c|c|}
\hline & \multicolumn{4}{|c|}{ Sustainability Design } & \multicolumn{4}{|c|}{ Commercialization } \\
\hline & \multicolumn{2}{|c|}{ China $(N=516)$} & \multicolumn{2}{|c|}{ U.S. $(N=389)$} & \multicolumn{2}{|c|}{ China $(N=516)$} & \multicolumn{2}{|c|}{ U.S. $(N=389)$} \\
\hline & $\beta$ (S.E.) & Std $\beta$ & $\beta$ (S.E.) & Std $\beta$ & $\beta$ (S.E.) & Std $\beta$ & $\beta($ S.E.) & $\operatorname{Std} \beta$ \\
\hline Intercept & $\begin{array}{c}1.146^{* * *} \\
(0.265)\end{array}$ & 0.000 & $\begin{array}{l}0.636^{* *} \\
(0.293)\end{array}$ & 0.000 & $\begin{array}{c}4.389 * * * \\
(0.230)\end{array}$ & 0.000 & $\begin{array}{c}2.835^{* * *} \\
(0.334)\end{array}$ & 0.000 \\
\hline BDAC & $\begin{array}{c}0.323^{* * *} \\
(0.044)\end{array}$ & 0.294 & $\begin{array}{c}0.549^{* * *} \\
(0.045)\end{array}$ & 0.499 & $\begin{array}{c}0.178^{* * *} \\
(0.039)\end{array}$ & 0.212 & $\begin{array}{c}0.265^{* * *} \\
(0.052)\end{array}$ & 0.244 \\
\hline AIC & $\begin{array}{c}0.402 * * * * \\
(0.042)\end{array}$ & 0.383 & $\begin{array}{c}0.244^{* * *} \\
(0.038)\end{array}$ & 0.266 & $\begin{array}{c}0.181^{* * *} \\
(0.037)\end{array}$ & 0.226 & $\begin{array}{c}0.274^{* * * *} \\
(0.043)\end{array}$ & 0.303 \\
\hline F-value & $128.800 * * *$ & & $125.250 * * *$ & & $41.580 * * *$ & & $45.990 * * *$ & \\
\hline $\mathrm{R}^{2}$ & 0.334 & & 0.394 & & 0.140 & & 0.192 & \\
\hline Adj- $R^{2}$ & 0.332 & & 0.390 & & 0.136 & & 0.188 & \\
\hline
\end{tabular}

Note: ${ }^{* * *} p<0.01 ;{ }^{* *} p<0.05 ;{ }^{*} p<0.10$ (two-tailed test). $\beta$ represents parameter estimate; S.E. represents standard error; Std $\beta$ represents standardized estimate. 
Table 7. Regression results of the innovation process on sustainable growth and performance.

\begin{tabular}{|c|c|c|c|c|c|c|c|c|}
\hline & \multicolumn{4}{|c|}{ Average Sales Growth (\%) } & \multicolumn{4}{|c|}{ Average Gross Margin (\%) } \\
\hline & \multicolumn{2}{|c|}{ China $(N=516)$} & \multicolumn{2}{|c|}{ U.S. $(N=389)$} & \multicolumn{2}{|c|}{ China $(N=516)$} & \multicolumn{2}{|c|}{ U.S. $(N=389)$} \\
\hline & $\beta$ (S.E.) & Std $\beta$ & $\beta$ (S.E.) & Std $\beta$ & $\beta$ (S.E.) & Std $\beta$ & $\beta($ S.E.) & Std $\beta$ \\
\hline Intercept & $\begin{array}{c}-30.442 * * * \\
(7.242)\end{array}$ & 0.000 & $\begin{array}{c}-14.011 \\
(9.964)\end{array}$ & 0.000 & $\begin{array}{c}1.936 \\
(4.736)\end{array}$ & 0.000 & $\begin{array}{c}7.469 \\
(10.256)\end{array}$ & 0.000 \\
\hline $\begin{array}{l}\text { Sustainability } \\
\text { Design }\end{array}$ & $\begin{array}{c}7.095^{* * *} \\
(0.689)\end{array}$ & 0.399 & $\begin{array}{c}6.686^{* * *} \\
(1.173)\end{array}$ & 0.272 & $\begin{array}{l}4.728^{* * *} \\
(0.451)\end{array}$ & 0.401 & $\begin{array}{c}6.572^{* * *} \\
(1.207)\end{array}$ & 0.258 \\
\hline Commercialization & $\begin{array}{l}6.008^{* * *} \\
(0.900)\end{array}$ & 0.258 & $\begin{array}{c}6.528^{* * *} \\
(1.194)\end{array}$ & 0.262 & $\begin{array}{c}4.408^{* * *} \\
(0.589)\end{array}$ & 0.285 & $\begin{array}{c}7.525^{* * *} \\
(1.229)\end{array}$ & 0.291 \\
\hline Industry 1 & $\begin{array}{l}4.552 \\
(7.356)\end{array}$ & 0.026 & $\begin{array}{l}-8.047 \\
(9.873)\end{array}$ & -0.044 & $\begin{array}{l}1.194 \\
(4.810)\end{array}$ & 0.010 & $\begin{array}{l}-10.376 \\
(10.162)\end{array}$ & -0.054 \\
\hline Industry 2 & $\begin{array}{l}-0.618 \\
(4.302)\end{array}$ & -0.007 & $\begin{array}{l}-6.107 \\
(7.223)\end{array}$ & -0.053 & $\begin{array}{c}4.196 \\
(2.813)\end{array}$ & 0.069 & $\begin{array}{l}-5.059 \\
(7.435)\end{array}$ & -0.042 \\
\hline Industry 3 & $\begin{array}{l}-4.977 \\
(5.068)\end{array}$ & -0.044 & $\begin{array}{l}-5.681 \\
(7.820)\end{array}$ & -0.043 & $\begin{array}{l}-0.889 \\
(3.314)\end{array}$ & -0.012 & $\begin{array}{l}-6.993 \\
(8.049)\end{array}$ & -0.051 \\
\hline Industry 4 & $\begin{array}{l}1.164 \\
(5.573)\end{array}$ & 0.009 & $\begin{array}{l}-10.400 \\
(8.153)\end{array}$ & -0.075 & $\begin{array}{l}3.348 \\
(3.645)\end{array}$ & 0.040 & $\begin{array}{c}-13.455 \\
(8.392)\end{array}$ & -0.093 \\
\hline F-value & $29.070 * * *$ & & $14.640^{* * *}$ & & $32.060 * * *$ & & $16.020 * * *$ & \\
\hline R2 & 0.255 & & 0.187 & & 0.274 & & 0.201 & \\
\hline Adj-R2 & 0.247 & & 0.174 & & 0.266 & & 0.189 & \\
\hline
\end{tabular}

Note: ${ }^{* * *} p<0.01 ;{ }^{* *} p<0.05 ;{ }^{*} p<0.10$ (two-tailed test). $\beta$ represents parameter estimate; S.E. represents standard error; Std $\beta$ represents standardized estimate. Industry $1=$ hotel, traveling, and tourism services; Industry 2 = banking, insurances, securities, financial investments, and related activities; Industry $3=$ information and semiconductor; Industry $4=$ Internet-related services; Industry $5=$ health care services. Industry 5 is the baseline.

The dependent variables in Table 7 are three-year average sales growth and three-year average gross margin, which are in percentages. The interpretation of the regression results in Table 7 needs some cautions. For example, in China (columns 1 and 5), a one-unit increase in sustainability design will increase average sales growth by $7.095 \%$ (column 1 ) and average gross margin by $4.728 \%$ (column 5 ).

H5 proposed that proficiency in sustainability design increases sustainable growth and performance. For both countries, results in Table 7 indicate that the regression coefficients of sustainability design for average sales growth $\left(\beta_{\text {China }}=7.095 ; \beta_{\text {U.S. }}=6.686\right)$ and for average gross margin $\left(\beta_{\text {China }}=4.728 ; \beta_{\text {U.S. }}=6.572\right)$ were significantly positive $(p<0.01)$. These results confirm that increased proficiency in sustainability design increases sustainable growth and performance, supporting $\mathrm{H} 5$.

H6 hypothesized that proficiency in commercialization enhances sustainable growth and performance. For China and the United States, the results in Table 7 also indicate that the regression coefficients of commercialization for average sales growth $\left(\beta_{\text {China }}=6.008 ; \beta_{\text {U.S. }}=6.528\right)$ and for average gross margin ( $\left.\beta_{\text {China }}=4.408 ; \beta_{\text {U.S. }}=7.525\right)$ are significantly positive $(p<0.01)$. These results provide empirical supports for $\mathrm{H} 6$.

\subsection{Mediating Effects of Sustainability Design and Commercialization}

We performed two mediation tests to answer our third research question (RQ3): How do sustainability design and commercialization mediate the relationships between BDAC and AIC and sustainable growth and performance of sustainability development projects? The first test was the mediation effect test proposed by Baron and Kenny [47] and the second test was the Sobel test [48].

\subsubsection{Mediation Effect Test by Baron and Kenny}

Baron and Kenny's [47] mediation effect test method involves three regression models: independent variable to mediator variable (Model 1), independent variable to dependent variable (Model 2), independent variable and mediator variable to dependent variable (Model 3). To verify the mediating effect, the following conditions must be met: (1) the independent variable has a significant effect on the mediating variable, (2) the independent variable has a significant effect on the dependent variable, and (3) the mediating variable has a significant effect on the dependent variable. If the regression 
coefficient of the independent variable in Model 3 is not significant, there is full mediation; if the regression coefficient of the independent variable in Model 3 is significant and the coefficient is smaller than the coefficient in Model 2, there is only partial mediation. Tables 8 and 9 present the regression results of Model 2 and Model 3, respectively.

Table 8. Regression results of the BDAC and AIC on sustainable growth and performance.

\begin{tabular}{|c|c|c|c|c|c|c|c|c|}
\hline & \multicolumn{4}{|c|}{ Average Sales Growth (\%) } & \multicolumn{4}{|c|}{ Average Gross Margin (\%) } \\
\hline & \multicolumn{2}{|c|}{ China $(N=516)$} & \multicolumn{2}{|c|}{ U.S. $(N=389)$} & \multicolumn{2}{|c|}{ China $(N=516)$} & \multicolumn{2}{|c|}{ U.S. $(N=389)$} \\
\hline & $\begin{array}{c}\beta \\
\text { (S.E.) }\end{array}$ & Std $\beta$ & $\begin{array}{c}\beta \\
\text { (S.E.) }\end{array}$ & Std $\beta$ & $\begin{array}{c}\beta \\
\text { (S.E.) }\end{array}$ & Std $\beta$ & $\begin{array}{c}\beta \\
\text { (S.E.) }\end{array}$ & Std $\beta$ \\
\hline Intercept & $\begin{array}{c}-11.584 * \\
(5.954)\end{array}$ & 0.000 & $\begin{array}{c}-23.270^{* *} \\
(9.599)\end{array}$ & 0.000 & $\begin{array}{c}18.119^{* * *} \\
(3.956)\end{array}$ & 0.000 & $\begin{array}{c}2.468 \\
(10.004)\end{array}$ & 0.000 \\
\hline BDAC & $\begin{array}{c}6.009^{* * *} \\
(0.863)\end{array}$ & 0.307 & $\begin{array}{c}9.619^{* * *} \\
(1.264)\end{array}$ & 0.356 & $\begin{array}{c}4.554^{* * *} \\
(0.573)\end{array}$ & 0.351 & $\begin{array}{c}9.995^{* * *} \\
(1.317)\end{array}$ & 0.357 \\
\hline AIC & $\begin{array}{c}4.262^{* * *} \\
(0.825)\end{array}$ & 0.228 & $\begin{array}{c}5.284^{* * *} \\
(1.050)\end{array}$ & 0.235 & $\begin{array}{c}2.091^{* * *} \\
(0.548)\end{array}$ & 0.169 & $\begin{array}{c}5.112 * * * \\
(1.094)\end{array}$ & 0.219 \\
\hline $\begin{array}{c}\text { Industry } \\
1\end{array}$ & $\begin{array}{c}1.481 \\
(7.546)\end{array}$ & 0.008 & $\begin{array}{c}-10.329 \\
(9.567)\end{array}$ & -0.056 & $\begin{array}{r}-0.680 \\
(5.014)\end{array}$ & -0.006 & $\begin{array}{c}-12.964 \\
(9.971)\end{array}$ & -0.068 \\
\hline $\begin{array}{c}\text { Industry } \\
2\end{array}$ & $\begin{array}{l}-1.210 \\
(4.410)\end{array}$ & -0.013 & $\begin{array}{c}-10.515 \\
(7.008)\end{array}$ & -0.091 & $\begin{array}{c}3.754 \\
(2.930)\end{array}$ & 0.062 & $\begin{array}{l}-9.738 \\
(7.304)\end{array}$ & -0.081 \\
\hline $\begin{array}{c}\text { Industry } \\
3\end{array}$ & $\begin{array}{l}-8.249 \\
(5.195)\end{array}$ & -0.073 & $\begin{array}{l}-6.316 \\
(7.583)\end{array}$ & -0.048 & $\begin{array}{l}-2.994 \\
(3.452)\end{array}$ & -0.040 & $\begin{array}{l}-7.511 \\
(7.903)\end{array}$ & -0.055 \\
\hline $\begin{array}{c}\text { Industry } \\
4\end{array}$ & $\begin{array}{c}2.796 \\
(5.718)\end{array}$ & 0.022 & $\begin{array}{c}-10.909 \\
(7.892)\end{array}$ & -0.079 & $\begin{array}{c}4.125 \\
(3.799)\end{array}$ & 0.049 & $\begin{array}{c}-14.467 \text { * } \\
(8.226)\end{array}$ & -0.100 \\
\hline F-value & $23.350 * * *$ & & $19.620^{* * *}$ & & $22.710^{* * *}$ & & $18.980^{* * *}$ & \\
\hline R2 & 0.216 & & 0.236 & & 0.211 & & 0.230 & \\
\hline Adj-R2 & 0.207 & & 0.224 & & 0.202 & & 0.218 & \\
\hline
\end{tabular}

Note: ${ }^{* * *} p<0.01 ;{ }^{* *} p<0.05 ;{ }^{*} p<0.10$ (two-tailed test). $\beta$ represents parameter estimate; S.E. represents standard error; Std $\beta$ represents standardized estimate. Industry $1=$ hotel, traveling, and tourism services; Industry 2 = banking, insurances, securities, financial investments, and related activities; Industry $3=$ information and semiconductor; Industry $4=$ Internet-related services; Industry $5=$ health care services. Industry 5 is the baseline.

Table 9. Regression results of the BDAC and AIC and innovation process on sustainable growth and performance.

\begin{tabular}{|c|c|c|c|c|c|c|c|c|}
\hline & \multicolumn{4}{|c|}{ Average Sales Growth (\%) } & \multicolumn{4}{|c|}{ Average Gross Margin (\%) } \\
\hline & \multicolumn{2}{|c|}{ China $(N=516)$} & \multicolumn{2}{|c|}{ U.S. $(N=389)$} & \multicolumn{2}{|c|}{ China $(N=516)$} & \multicolumn{2}{|c|}{ U.S. $(N=389)$} \\
\hline & $\begin{array}{c}\text { B } \\
\text { (S.E.) }\end{array}$ & Std $\beta$ & $\begin{array}{c}\beta \\
\text { (S.E.) }\end{array}$ & Std $\beta$ & $\begin{array}{c}\beta \\
\text { (S.E.) }\end{array}$ & Std $\beta$ & $\begin{array}{c}\beta \\
\text { (S.E.) }\end{array}$ & Std $\beta$ \\
\hline Intercept & $\begin{array}{c}-37.395^{* * *} \\
(7.241)\end{array}$ & 0.000 & $\begin{array}{c}-36.440 * * * \\
(10.240)\end{array}$ & 0.000 & $\begin{array}{l}-2.315 \\
(4.734)\end{array}$ & 0.000 & $\begin{array}{l}-14.166 \\
(10.597)\end{array}$ & 0.000 \\
\hline BDAC & $\begin{array}{c}3.648^{* * *} \\
(0.888)\end{array}$ & 0.186 & $\begin{array}{c}7.669^{* * *} \\
(1.505)\end{array}$ & 0.284 & $\begin{array}{c}2.762^{* * *} \\
(0.580)\end{array}$ & 0.213 & $\begin{array}{c}7.729^{* * *} \\
(1.557)\end{array}$ & 0.276 \\
\hline AIC & $\begin{array}{c}1.418 \\
(0.884)\end{array}$ & 0.076 & $\begin{array}{c}3.793^{* * *} \\
(1.143)\end{array}$ & 0.169 & $\begin{array}{l}-0.058 \\
(0.578)\end{array}$ & -0.005 & $\begin{array}{c}3.299^{* * *} \\
(1.183)\end{array}$ & 0.141 \\
\hline $\begin{array}{l}\text { Sustainability } \\
\text { Design }\end{array}$ & $\begin{array}{l}4.994^{* * *} \\
(0.830)\end{array}$ & 0.281 & $\begin{array}{c}1.677 \\
(1.397)\end{array}$ & 0.068 & $\begin{array}{c}3.665^{* * *} \\
(0.542)\end{array}$ & 0.311 & $\begin{array}{c}1.711 \\
(1.445)\end{array}$ & 0.067 \\
\hline Commercialization & $\begin{array}{l}4.395^{* * *} \\
(0.953)\end{array}$ & 0.188 & $\begin{array}{c}3.953^{* * *} \\
(1.231)\end{array}$ & 0.159 & $\begin{array}{c}3.562 * * * \\
(0.623)\end{array}$ & 0.231 & $\begin{array}{l}5.097^{* * *} \\
(1.274)\end{array}$ & 0.197 \\
\hline Industry 1 & $\begin{array}{c}3.603 \\
(7.214)\end{array}$ & 0.020 & $\begin{array}{l}-9.141 \\
(9.457)\end{array}$ & -0.050 & $\begin{array}{c}0.877 \\
(4.716)\end{array}$ & 0.007 & $\begin{array}{c}-11.410 \\
(9.787)\end{array}$ & -0.060 \\
\hline Industry 2 & $\begin{array}{l}-0.258 \\
(4.216)\end{array}$ & -0.003 & $\begin{array}{l}-9.083 \\
(6.938)\end{array}$ & -0.078 & $\begin{array}{c}4.437 \\
(2.756)\end{array}$ & 0.073 & $\begin{array}{l}-8.008 \\
(7.179)\end{array}$ & -0.066 \\
\hline Industry 3 & $\begin{array}{l}-5.565 \\
(4.975)\end{array}$ & -0.049 & $\begin{array}{l}-6.731 \\
(7.501)\end{array}$ & -0.051 & $\begin{array}{l}-0.926 \\
(3.253)\end{array}$ & -0.012 & $\begin{array}{l}-8.154 \\
(7.762)\end{array}$ & -0.060 \\
\hline Industry 4 & $\begin{array}{c}1.604 \\
(5.469)\end{array}$ & 0.013 & $\begin{array}{l}-9.181 \\
(7.811)\end{array}$ & -0.066 & $\begin{array}{l}3.296 \\
(3.576)\end{array}$ & 0.039 & $\begin{array}{c}-12.293 \\
(8.083)\end{array}$ & -0.085 \\
\hline F-value & $25.610^{* * *}$ & & $16.540^{* * *}$ & & $27.990^{* * *}$ & & $16.960^{* * *}$ & \\
\hline R2 & 0.288 & & 0.258 & & 0.306 & & 0.263 & \\
\hline Adj-R2 & 0.277 & & 0.243 & & 0.295 & & 0.248 & \\
\hline
\end{tabular}

Note: ${ }^{* * *} p<0.01 ;{ }^{* *} p<0.05 ;{ }^{*} p<0.10$ (two-tailed test). $\beta$ represents parameter estimate; S.E. represents standard error; Std $\beta$ represents standardized estimate. Industry $1=$ hotel, traveling, and tourism services; Industry 2 = banking, insurances, securities, financial investments, and related activities; Industry $3=$ information and semiconductor; Industry $4=$ Internet-related services; Industry $5=$ health care services. Industry 5 is the baseline. 
In the China sample, the results suggest that the innovation process partly mediates the relationship between BDAC and sustainable growth and performance $(p<0.01)$. It fully mediates the relationship between AIC and sustainable growth and performance $(p<0.01)$.

In the U.S. sample, the results show that sustainability design has no significant effects on sustainable growth and performance $(p>0.10)$, which indicates that there is no mediation effect between two emerging capabilities and sustainable growth and performance. Conversely, commercialization partly mediates this relationship.

\subsubsection{The Sobel Test}

Preacher et al. [48] argued that the Sobel test is a more powerful alternative for assessing indirect effects because the Sobel test can directly evaluate mediation. As an additional analysis, we performed the Sobel test using the following equation:

$$
\text { z-value }=\mathrm{a} \times \mathrm{b} / \mathrm{SQRT}\left(\mathrm{b}^{2} \times \mathrm{s}_{\mathrm{a}}{ }^{2}+\mathrm{a}^{2} \times \mathrm{s}_{\mathrm{b}}{ }^{2}\right),
$$

where $\mathrm{a}=$ unstandardized regression coefficient for the association between independent variable (BDAC or AIC) and mediator (sustainability design or commercialization); $\mathrm{s}_{\mathrm{a}}=$ standard error of $\mathrm{a}$; $\mathrm{b}=$ unstandardized regression coefficient for the association between the mediator (sustainability design or commercialization) and the dependent variable (average sales growth or average gross margin), when the independent variable (IV) is also a predictor of the dependent variable (DV); $\mathrm{s}_{\mathrm{b}}=$ standard error of $\mathrm{b}$.

Table 10 presents the results of the Sobel test. The results suggest that the mediating effects of the innovation process (sustainability design and commercialization) on the relationship between emerging capabilities (BDAC and AIC) and sustainable growth and performance passed the Sobel test $(p<0.01)$. Therefore, we concluded that the answer to RQ3 is "yes".

Table 10. Sobel test for indirect effects.

\begin{tabular}{|c|c|c|c|c|}
\hline & \multicolumn{4}{|c|}{ Average Sales Growth (\%) } \\
\hline & \multicolumn{2}{|c|}{ China $(N=516)$} & \multicolumn{2}{|c|}{ U.S. $(N=389)$} \\
\hline & $\begin{array}{l}\text { Sustainability } \\
\text { Design }\end{array}$ & Commercialization & $\begin{array}{l}\text { Sustainability } \\
\text { Design }\end{array}$ & Commercialization \\
\hline BDAC & $\begin{array}{c}5.978^{* * *} \\
(0.383)\end{array}$ & $\begin{array}{c}3.768^{* * *} \\
(0.284)\end{array}$ & $\begin{array}{c}5.164^{* * *} \\
(0.711)\end{array}$ & $\begin{array}{l}3.728 * * * \\
(0.464)\end{array}$ \\
\hline \multirow{5}{*}{ AIC } & $7.010^{* * *}$ & $3.946^{* * *}$ & $4.263^{* * *}$ & $4.149^{* * *}$ \\
\hline & $(0.407)$ & $(0.276)$ & $(0.383)$ & $(0.431)$ \\
\hline & \multicolumn{4}{|c|}{ Average Gross Margin (\%) } \\
\hline & \multicolumn{2}{|c|}{ China $(N=516)$} & \multicolumn{2}{|c|}{ U.S. $(N=389)$} \\
\hline & $\begin{array}{l}\text { Sustainability } \\
\text { Design }\end{array}$ & Commercialization & $\begin{array}{l}\text { Sustainability } \\
\text { Design }\end{array}$ & Commercialization \\
\hline & $6.013 * * *$ & $3.897 * * *$ & $5.164^{* * *}$ & $3.917^{* * *}$ \\
\hline BDAC & $(0.254)$ & $(0.201)$ & $(0.711)$ & $(0.509)$ \\
\hline & $7.068^{* * *}$ & $4.095^{* * *}$ & $4.263^{* * *}$ & $4.415^{* * *}$ \\
\hline AIC & $(0.269)$ & $(0.195)$ & $(0.383)$ & $(0.467)$ \\
\hline
\end{tabular}

Note: ${ }^{*} p<0.10{ }^{* *} p<0.05 .{ }^{* * *} p<0.01$ (two-tailed). Sobel tests were conducted using the estimates from the model with main effects.

\subsection{Cross-National Comparison}

By further examination of the unstandardized coefficients reported in Tables 6 and 7, we found some cross-national differences. In China, the results in Table 6 suggest that when BDAC and AIC increase by one unit, the proficiency of sustainability design increases by 0.323 and 0.402 , respectively. 
Similarly, increasing one unit of BDAC and AIC increases the proficiency of commercialization by 0.178 and 0.181 , respectively. Therefore, AIC has a greater effect on both sustainability design and commercialization than that of BDAC in China. Hao et al. [1] explored the moderating effect of BDAC between big data and sustainable innovation performance, and they found that the moderating effect of BDAC was different in the Chinese sample and U.S. sample. Specifically, BDAC strengthened the relationship between big data and sustainable innovation performance in the U.S. sample. However, in the Chinese sample, BDAC exerted a positive moderating effect before a certain point, and after this point, BDAC exerted a negative moderating effect [1]. Different from Hao et al. [1], we focused on two emerging capabilities and the most important innovation process, and found that the effect of BDAC and AIC on sustainability design and commercialization is different, added the research on cross-national differences.

In the United States, a one-unit increase in BDAC and AIC increases the proficiency of sustainability design by 0.549 and 0.244 , respectively. These results suggest that relative to BDAC, AIC has lower effects on increasing the proficiency of sustainability design in the United States. Conversely, a one-unit increase in BDAC and AIC increases the proficiency of commercialization by 0.265 and 0.274 , respectively. Thus, relative to BDAC, AIC has higher, not lower, effects on proficiency of commercialization. Hao et al. [1] called for AIC to be considered; we found that the relative importance of BDAC and AIC is different for sustainability design and commercialization, our results enrich the literature on cross-national comparative studies of BDAC and AIC.

The results in Table 8 indicate that there are cross-national similarities in the relative direct effects of BDAC and AIC on sustainable growth and performance. In China, the regression coefficients of BDAC and AIC for average sales growth are $6.009 \%$ and $4.262 \%(p<0.01)$, respectively. The regression coefficients for average gross margin are $4.554 \%$ and $2.091 \%(p<0.01)$, respectively. Thus, in China, the direct effects of BDAC on sustainable growth and performance are higher than that of AIC. These cross-national similarities in the relative direct effects of BDAC and AIC on sustainable growth and performance adds to our current knowledge of cross-national comparison of emerging technology capabilities.

In the United States, a one-unit increase in BDAC and AIC increases average sales growth by $9.619 \%$ and $5.284 \%$ and average gross margin by $9.995 \%$ and $5.112 \%(p<0.01)$, respectively. Thus, the same as in China, BDAC has greater effects on sustainable growth and performance than AIC does. This adds to our current understanding of the cross-national differences between the United States and China.

\section{Discussion}

\subsection{Results}

This study focused on sustainability development projects, and proposed a theoretical model based on the SPP framework [16] to investigate the impact of two emerging capabilities on the proficiency of the innovation process and on sustainable growth and performance, as well as the mediating effects of the innovation process. Consistent with prior studies, BDAC and AIC had a positive impact on sustainable organizational performance $[1,9,10]$.

The empirical results from two countries revealed several interesting cross-national similarities for both China and the United States. First, BDAC and AIC have significant positive impacts on the proficiency of both sustainability design and commercialization. By examination of the measures of BDAC, the results suggest that BDAC can help companies extract valuable information from big data to identify customer needs, predict customer behavior, locate target customer groups, improve the efficiency of advertising, ensure effective service launch, and so on $[1,11,17,20]$. AIC can help managers to make decisions, speed up the process of decision-making, and improve the accuracy of decision-making [21]. 
Second, the proficiency of the innovation process (specifically sustainability design and commercialization) has a significant positive impact on sustainable growth and performance. These results add to our existing knowledge that the innovation process increases innovation performance $[4,5]$. Research and development personnel should pay close attention to customers' needs in product design and recognize the importance of marketing in new product management; not doing so may lead to the failure of product innovation projects [5]. In addition, distribution and promotion strategies play a vital role in improving market share and profitability [6].

Third, the innovation process mediates the relationship between emerging capabilities and sustainable growth and performance. Both BDAC and AIC improve sustainable growth and performance through sustainability design and commercialization. In addition, the results indicate that BDAC has greater effects on sustainable growth and performance than AIC does. These results offer important extensions to a recent study of big data and BDAC [1].

The cross-national analyses also revealed interesting cross-national differences between China and the United States. First, AIC has greater effects on both sustainability design and commercialization than BDAC in China. In contrast, AIC has lower, not higher, effects on sustainability design in the United States. The same as in China, AIC also has greater effects on commercialization than BDAC in the United States. A plausible explanation may be that, because of the differences in the pace of data analytics development between China and the United States, it appears that Chinese firms are less effective than the U.S. companies in converting BDAC to produce and market a service innovation.

Second, sustainability design is more important than commercialization for both average sales growth and average gross margin in China. Yet, for the United States, sustainability design is only more important than commercialization for increasing average sales growth. It is less, not more, important than commercialization in increasing average gross margin. Therefore, companies in different countries should evaluate their innovation objectives (sales, profitability, or both) in order to adopt different investment strategies to increase the proficiency of the innovation process.

\subsection{Theoretical Contributions}

This study contributes to the literature in several ways. First, SPP framework [16] emphasized that the sources of advantages (e.g., resources and capabilities) improve sustainable organizational performance through creating sustainable positional advantages. The SPP framework has been adopted in many innovation and entrepreneurship studies. For example, Zhao et al. [31] suggested that scalability and protectability together mediate the relationship between market-linking capability and performance and the relationship between service design capabilities and performance. Song et al. [6] adopted the SPP framework to study new product development in the United States and Japan. SIM [4] proposed that service performance was affected by five innovation process and five service quality dimensions, the results identified that service design and commercialization are two most important stages of the innovation process. We developed a theoretical model based on the SPP framework [16] and the SIM [4] to examine how BDAC and AIC affect the innovation process and sustainable growth and performance. Our findings add to the literature on BDAC, AIC, and the innovation process and extend the SPP theoretical model to examine the effects of these two emerging capabilities.

Second, we investigated the mediating effects of the innovation process on the relationships between BDAC and AIC and sustainable growth and performance. Prior studies have evaluated the mediating variables between BDAC and firm performance. For example, some studies have found that knowledge management [10] and process-oriented dynamic capabilities [11] mediate the relationship between BDAC and sustainable organizational performance. Empirical research on AIC is relatively limited. We investigated the mediating effects of the two most important stages of the innovation process. Therefore, our research findings add to prior research on the direct effect of BDAC on sustainable competitive advantage $[1,20]$ and on sustainable organizational performance $[1,9-11]$. The results regarding the mediating effects of sustainability design and commercialization add to previous studies on the mediating role of dynamic capabilities [11] and knowledge management [10]. 
Third, while most of the existing studies on BDAC have focused on manufacturing industries [19], we collected data on sustainable service development projects from two countries to validate the theoretical model. Therefore, this study supplements existing research and enriches the cross-national comparison research [1].

Fourth, while past research on artificial intelligence (AI) has focused on computational tools, algorithms, and technical aspects of AI [21,30,40], we transformed these technical functions to capability perspective, developed, and validated the AIC scale with data from China and the United States. In addition, Hao et al. [1] called for future research to include AIC. We integrated AIC into our theoretical model to study how BDAC and AIC jointly affect the proficiency of the innovation process in the development of sustainable products and services. These contributions add to the sustainable development literature.

\subsection{Management Implications}

Our findings can be useful to innovation managers for identifying capabilities to improve the proficiency of their innovation process and thereby enhance sustainable growth and performance. To improve sustainable sales growth and gross margin, both Chinese and U.S. companies should invest in building BDAC, because it generates greater improvements in sustainable growth and performance. Based on an examination of our BDAC measures, to increase sustainable performance, organizations should increase investment in developing the following BDAC areas: (1) ability to use analytics and algorithms to extract value from big data; (2) capability to discover relationships and dependencies from big data; (3) capability to perform predictions of outcomes and behaviors from big data; and (4) capability to discover new correlations from big data to discover market demand trends and predict user behavior. Furthermore, if companies have extra resources, they should then invest in developing AIC in the following areas: (1) capability to develop human-inspired algorithms to predict customer behavior; (2) capability to develop devices to replicate human intelligence and other cognitive functions; and (3) capability to develop artificial intelligence for learning from the acquisition of information to accurate rules for using the information, using rules to reach approximate or definite conclusions, and self-correction.

Our study results also indicate how BDAC and AIC can improve sustainable growth and performance by improving the proficiency of sustainability design and commercialization. Both Chinese and U.S. companies can effectively allocate their limited resources to improve the proficiency of sustainability design by developing a clear value proposition of the service, designing the service to ensure that it is easy to scale up, designing the service to ensure that it delivers the promised value proposition, and integrating state-of-the-art sustainable technologies into the sustainability design.

Then, if companies have additional resources available, they should improve the proficiency of commercialization by setting appropriate pricing levels, launching the service with strong promotional programs, launching the service with effective advertising, launching the service with excellent selling effort (e.g., deploying properly trained people), and launching the service with excellent distribution (e.g., on-time delivery, quick response).

Companies can also improve the proficiency of their innovation process by building their BDAC and AIC. To improve the proficiency of commercialization, sustainability development projects in China and the United States should first build their AIC and then invest in BDAC. To improve the proficiency of sustainability design, managers of sustainability development projects in China should first build a high level of AIC. In contrast, managers of sustainability development projects in the United States should focus on building high-level BDAC rather than AIC.

\subsection{Research Limitations and Future Directions}

This study had several limitations to be noted. First, this study only included BDAC and AIC in the model. Future research should also include emerging capabilities (e.g., machine-learning capability) [1]. Second, although scholars generally divide the innovation process into several stages, this study only 
focused on sustainability design and commercialization. Future research should consider other stages, such as idea screening, business and market opportunity analysis, and service testing [4]. Third, due to limited resources, we collected data only from China and the United States. Data from other countries should be included in future data collection to enrich cross-national comparative research. Fourth, we used three-year average sales growth and three-year gross margin as proxies for sustainable growth and performance. Future research should collect performance data over a longer term as well as other data using other measures of sustainable growth and performance.

\section{Conclusions}

This study contributes to sustainable development theory. Our findings revealed several interesting results for enhancing the sustainability of innovation and organizational growth: (1) For both China and the United States, both BDAC and AIC increase the proficiency of sustainability design and commercialization, with AIC having a greater impact on the proficiency of commercialization. (2) For both countries, both BDAC and AIC have direct positive impacts on sustainable growth and performance, with BDAC having a greater impact. (3) Sustainability design and commercialization have positive effects on sustainable growth and performance, with sustainability design having a greater impact on average sales growth. (4) Sustainability design and commercialization mediate the positive effects of BDAC and AIC on sustainable growth and performance. (5) There are two differences between the Chinese and U.S. samples: first, AIC appears to be more important for sustainability design in China than in the United States, while BDAC appears to be more important in the United States than in China. Second, sustainability design appears to be more important for average gross margin in China than in the United States, while commercialization appears to be more important in the United States than in China.

Author Contributions: Conceptualization, M.S., H.H., and H.Z.; methodology, M.S., and H.Z.; data curation, M.S. and H.Z.; writing — original draft preparation, H.H., H.Z., and M.S. writing-review and editing, M.S. and H.Z. All three authors share the first-authorship and contributed equally to the development of this research. All authors have read and agreed to the published version of the manuscript.

Funding: This research was funded by the Natural Science Foundation of Shaanxi Province of China, grant number 2018JQ7003; and Shaanxi Province of China, Department of Education Scientific Research Plan Projects, grant number 18JK0367.

Acknowledgments: The authors thank assistant editor, Carrie Liang, and two anonymous reviewers for their useful suggestions to an earlier version which improved the quality of this research. The literature review and hypothesis development were based the graduation thesis of Huanhuan He.

Conflicts of Interest: The authors declare no conflict of interest. The funders had no role in the design of the study; in the collection, analyses, or interpretation of data; in the writing of the manuscript, or in the decision to publish the results.

\section{Appendix A. Study Measures and Sources}

Big Data Analytics Capability (BDAC): The measures were adopted directly from the measures developed and reported by Hao et al. [1]. The BDAC data reported in this study were collected from the project leader and a senior manager who was in charge of the data management center in the organization. The BDAC variable is an average of the two ratings. Therefore, although these measures were the same as reported in [1], the data source differed from that of Hao et al. [1].

(1) We have advanced tools (analytics and algorithms) to extract values of the big data. $(0=$ no capability; 10 = very high level of capability; adapted from Dubey et al. [20]; Gupta and George [17]);

(2) Our capability to discover relationships and dependencies from the big data is: (new scale developed based on filed research);

(3) Our capability to perform predictions of outcomes and behaviors from the big data is: $(0=$ no capability; 10 = very high level of capability; adapted from Gupta et al. [17]); 
(4) Our capability to discover new correlations from the big data to spot market demand trends and predict user behavior is: $(0=$ no capability; $10=$ very high level of capability; adapted from Akter et al. [9]; Wamba et al. [11]);

(5) * Our big data analytics staff has the right skills to accomplish their jobs successfully. $(0=$ no capability; 10 = very high level of capability; adopted from Gupta et al. [17]).

\section{Artificial Intelligence Capability (AIC):}

(1) * Our capability for simulating human intelligence behavior in making prediction of customer decisions is: $(0=$ no capability; $10=$ very high level of capability; developed based on conceptualization in Salehia et al. [21]; Goyache et al. [34]);

(2) Our capability for developing human-inspired algorithms to predict customer behavior is: $(0=$ no capability; 10 = very high level of capability; adapted from Salehia et al. [21]);

(3) Our capability for developing devices to replicate human intelligence and other cognitive functions is: $(0=$ no capability; $10=$ very high level of capability; adopted from Kibria et al. [40]);

(4) Our capability for developing AI for learning (the acquisition of information and rules for using the information), reasoning (using rules to reach approximate or definite conclusions), and self-correction is: (new scale developed based on the field research reported in [1]).

Sustainability Design ( 0 = done very poorly or mistakenly omitted altogether; 10 = done excellently; adopted from Song et al. [4]):

(1) Developing a clear value proposition of the service;

(2) Designing the service to ensure that it is easy to scale up;

(3) Designing the service to ensure that it delivers the promised value proposition;

(4) Integrating state-of-art technologies into the service design;

(5) * Involving lead users in the service design process.

Commercialization $(0=$ done very poorly or mistakenly omitted altogether; $10=$ done excellently; adopted from Song et al. [4]):

(1) Setting appropriate pricing level(s);

(2) Launching the service with strong promotional programs;

(3) Launching the service with effective advertising;

(4) * Launching the service with excellent selling effort, e.g., the right people, properly trained, etc.;

(5) Launching the service with excellent distribution: on-time delivery, quick response.

Average Sales growth (\%); adopted from Hao et al. [1]

$=($ second year sales growth rate + third year sales growth rate $) / 2$,

where

second year sales growth rate $=($ second year sales - first year sales $) /($ first year sales $) \times 100$;

third year sales growth rate $=($ third year sales - second year sales $) /($ second year sales $) \times 100$.

Average gross margin (\%); adopted from Hao et al. [1]

$=($ first year gross margin + second year gross margin + third year gross margin $) / 3$,

where

gross margin $=($ total sales - total variable costs $) /$ total sales.

Note: "** indicates that the measurement item was deleted based on the measurement validation analysis.

\section{References}

1. Hao, S.; Zhang, H.; Song, M. Big data, big data analytics capability, and sustainable innovation performance. Sustainability 2019, 11, 7145. [CrossRef] 
2. Lytras, M.D.; Visvizi, A. Big data and their social impact: Preliminary study. Sustainability 2019, 11, 5067. [CrossRef]

3. Wilden, R.; Akaka, M.A.; Karpen, I.O.; Hohberger, J. The evolution and prospects of service dominant logic: An investigation of past, present, and future research. J. Serv. Res-US. 2017, 20, 1-17. [CrossRef]

4. Song, L.Z.; Song, M.; Di Benedetto, A. A staged service innovation model. Decision Sci. 2009, 40, 571-599. [CrossRef]

5. Calantone, R.J.; Schmidt, J.B.; Song, X.M. Controllable factors of new product success: A cross-national comparison. Market. Sci. 1996, 15, 341-358. [CrossRef]

6. Song, X.M.; Parry, M.E. A cross-national comparative study of new product development processes: Japan and the United States. J. Mark. 1997, 61,1-18. [CrossRef]

7. Zhao, Y.L.; Libaers, D.; Song, M. First product success: A mediated moderating model of resources, development team startup experience, and product-positioning strategy. J. Prod. Innovat. Manag. 2015, 32, 441-458. [CrossRef]

8. Mikalef, P.; Pappas, I.O.; Krogstie, J.; Giannakos, M. Big data analytics capabilities: A systematic literature review and research agenda. Inf Syst E-Bus Manage. 2017, 2, 1-32. [CrossRef]

9. Akter, S.; Wamba, S.F.; Gunasekaran, A.; Dubey, R.; Childe, S.J. How to improve firm performance using big data analytics capability and business strategy alignment? Int. J. Prod. Econ. 2016, 182, 113-131. [CrossRef]

10. Ferraris, A.; Mazzoleni, A.; Devalle, A.; Couturier, J. Big data analytics capabilities and knowledge management: Impact on firm performance. Manage. Decis. 2019, 57, 1923-1936. [CrossRef]

11. Wamba, S.F.; Gunasekaran, A.; Akter, S.; Ren, S.J.; Dubey, R.; Childe, S.J. Big data analytics and firm performance: Effect of dynamic capabilities. J. Bus. Res. 2016, 70, 356-365. [CrossRef]

12. Garmaki, M.; Boughzala, I.; Wamba, S.F. The effect of big data analytics capability on firm performance. In Proceedings of the 20th Pacific Asia Conference on Information Systems, Chiayi, Taiwan, 27 June1 July 2016.

13. Oke, S.A. A literature review on artificial intelligence. Int. J. Inform. Manage. Sci. 2008, 19, 535-570.

14. Elia, G.; Margherita, A.; Passiante, G. Digital entrepreneurship ecosystem: How digital technologies and collective intelligence are reshaping the entrepreneurial process. Technol. Forecast. Soc. 2020, 150, 119791. [CrossRef]

15. Klumpp, M.; Zijm, H. Logistics innovation and social sustainability: How to prevent an artificial divide in human-computer interaction. J. Bus. Logist. 2019, 40, 265-278. [CrossRef]

16. Day, G.S.; Wensley, R. Assessing advantage: A framework for diagnosing competitive superiority. J. Marketing 1988, 52, 1-20. [CrossRef]

17. Gupta, M.; George, J.F. Toward the development of a big data analytics capability. Inform. Manage-Amster. 2016, 53, 1049-1064. [CrossRef]

18. Johnson, J.S.; Friend, S.B.; Lee, H.S. Big data facilitation, utilization, and monetization: Exploring the 3vs in a new product development process. J. Prod. Innovat. Manag. 2017, 34, 640-658. [CrossRef]

19. Arunachalam, D.; Kumar, N.; Kawalek, J.P. Understanding big data analytics capabilities in supply chain management: Unravelling the issues, challenges and implications for practice. Transport. Res. E-Log. 2017, 114, 416-436. [CrossRef]

20. Dubey, R.; Gunasekaran, A.; Childe, S.J. Big data analytics capability in supply chain agility: The moderating effect of organizational flexibility. Manag. Decis. 2019, 57, 2092-2112. [CrossRef]

21. Salehia, H.; Burgueño, R. Emerging artificial intelligence methods in structural engineering. Eng. Struct. 2018, 171, 170-189. [CrossRef]

22. Syam, N.; Sharma, A. Waiting for a sales renaissance in the fourth industrial revolution: Machine learning and artificial intelligence in sales research and practice. Ind. Market. Manag. 2018, 69, 135-146. [CrossRef]

23. Knoppe, M. Artificial intelligence as a decision tool for efficient strategic and operational management. Lect. Notes. Artif. Int. 2000, 1930, 17-19.

24. Correa, M.; Bielza, C.; Pamies-Teixeira, J. Comparison of Bayesian networks and artificial neural networks for quality detection in a machining process. Expert. Syst. Appl. 2009, 36, 7270-7279. [CrossRef]

25. Srivastava, S.K. Artificial intelligence: Way forward for India. J. Inform. Syst. Tech. Manag. 2018, 15, 1-23.

26. Wang, M.; Zhao, L.; Du, R.; Wang, C.; Chen, L.; Tian, L.; Stanley, H.E. A novel hybrid method of forecasting crude oil prices using complex network science and artificial intelligence algorithms. Appl. Energ. 2018, 220, 480-495. [CrossRef] 
27. Hao, S.; Song, M. Technology-driven strategy and firm performance: Are strategic capabilities missing links? J. Bus. Res. 2016, 69, 751-759. [CrossRef]

28. Menor, L.J.; Roth, A.V. New service development competence and performance: An empirical investigation in retail banking. Prod. Oper. Manag. 2008, 17, 267-284. [CrossRef]

29. De Jong, J.P.J.; Vermeulen, P.A.M. Organizing successful new service development: A literature review. Manag. Deci. 2003, 41, 844-858. [CrossRef]

30. Song, M.; Di Benedetto, C.A. Supplier's involvement and success of radical new product development in new ventures. J. Oper. Manag. 2008, 26, 1-22. [CrossRef]

31. Zhao, Y.L.; Song, M.; Storm, G.L. Founding team capabilities and new venture performance: The mediating role of strategic positional advantages. Entrep. Theory Pract. 2013, 37, 589-814. [CrossRef]

32. Song, X.M.; Thieme, R.J.; Xie, J. The impact of cross-functional joint involvement across product development stages: An exploratory study. J. Prod. Innovat. Manag. 1998, 15, 289-303. [CrossRef]

33. Xu, Z.; Frankwick, G.L.; Ramirez, E. Effects of big data analytics and traditional marketing analytics on new product success: A knowledge fusion perspective. J. Bus. Res. 2016, 69, 1562-1566. [CrossRef]

34. Goyache, F.; Bahamonde, A.; Alonso, J.; Lopez, S.; Coz, J.J.; Quevedo, J.R.; Ranilla, J.; Luaces, O.; Alvarezy, I.; Royoy, L.J.; et al. The usefulness of artificial intelligence techniques to assess subjective quality of products in the food industry. Trends Food Sci. Tech. 2001, 12, 370-381. [CrossRef]

35. Swink, M.; Song, M. Effects of marketing-manufacturing integration on new product development time and competitive advantage. J. Oper. Manag. 2007, 25, 203-217. [CrossRef]

36. Douglas, S.P.; Craig, C.S. International Marketing Research. Englewood Cliffs; Prentice-Hall, Inc.: Upper Saddle River, NJ, USA, 1983.

37. Song, X.M.; Parry, M.E. What separates Japanese new product winners from losers. J. Prod. Innovat. Manag. 1996, 13, 422-439. [CrossRef]

38. Churchill, G.A. A paradigm for developing better measures of marketing constructs. J. Marketing Res. 1979, 16, 64-73. [CrossRef]

39. Song, X.M.; Di Benedetto, C.A.; Zhao, Y.L. Pioneering advantages in manufacturing and service industries: Empirical evidence from nine countries. Strateg. Manage. J. 1999, 20, 811-836. [CrossRef]

40. Kibria, M.G.; Nguyen, K.; Villardi, G.P.; Zhao, O.; Ishizu, K.; Kojima, F. Big data analytics, machine learning, and artificial intelligence in next-generation wireless networks. IEEE Access 2018, 6, 32328-32338. [CrossRef]

41. Kuhlman, T.; Farrington, J. What is sustainability. Sustainability 2010, 2, 3436-3448. [CrossRef]

42. Ding, Y.; Nowak, E.; Zhang, H. Foreign vs. domestic listing: An entrepreneurial decision. J. Bus. Venturing 2010, 25, 175-191. [CrossRef]

43. Anderson, J.C.; Gerbing, D.W. Structured equation modeling in practice: A review and recommended two step approach. Psychol. Bull. 1988, 103, 411-423. [CrossRef]

44. Song, X.M.; Montoya-Weiss, M.M. The effect of perceived technological uncertainty on Japanese new product development. Acad. Manage. J. 2001, 44, 61-80.

45. Brown, T.A. Confirmatory Factor Analysis for Applied Research (Methodology in the Social Sciences); The Guilford Press: New York, NY, USA, 2006.

46. Fornell, C.; Larcker, D.F. Evaluating structured equation models, with unobservable variables and measurement error. J. Marketing Res. 1981, 18, 64-73. [CrossRef]

47. Baron, R.M.; Kenny, D.A. The moderator-mediator variable distinction in social psychological research: Conceptual, strategic, and statistical considerations. J. Pers. Soc. Psychol. 1986, 51, 1173-1182. [CrossRef] [PubMed]

48. Preacher, K.J.; Hayes, A.F. SPSS and SAS procedures for estimating indirect effects in simple mediation models. Behav. Res. Meth. Ins. C. 2004, 36, 717-731. [CrossRef] [PubMed]

(C) 2020 by the authors. Licensee MDPI, Basel, Switzerland. This article is an open access article distributed under the terms and conditions of the Creative Commons Attribution (CC BY) license (http://creativecommons.org/licenses/by/4.0/). 